\title{
Pathological studies in sinoatrial disorder (sick sinus syndrome)
}

\author{
ROGER EVANS AND DAVID B. SHAW \\ From the Department of Cardiology, Royal Devon and Exeter Hospital (Wonford), Exeter
}

Necropsy data from a series of 8 patients diagnosed during life as having chronic sinoatrial disorder (sick sinus syndrome) are presented. The morphology of the cardiac conducting system was studied by serial section, and the coronary vasculature was examined in detail in 5 of the 8 patients by the injection of a radiopaque medium, and in all 8 by routine histological methods. The sinoatrial nodes were found to be abnormal in 7 of the 8 patients. In 4 the node was atrophic, in 3 there was a pronounced increase in the amount of fibrous tissue present in the node, and in only one case did the node appear normal on light microscopy. In 1 of the 3 patients with fibrosed nodes amyloid tissue was found in the node itself, and heavy deposition was noted in the atrial musculature surrounding the node. The sinoatrial-node artery was patent in all cases and major narrowing of the larger coronary arteries was found in only 1 case. Histological abnormalities were found in the atrioventricular conducting tissue in all but 1 case, changes being seen either in the atrioventricular node or in the His-Purkinje system. It is concluded that the aetiology of sinoatrial disease is multifactorial, but that at least in the cases studied coronary arteriosclerosis was not responsible.

Since the description by Short (1954) of a syndrome of alternating bradycardia and tachycardia, there has been a growing volume of published reports on what has become known as sinoatrial disorder (Lloyd-Mostyn et al., 1973). There have been papers from several countries describing its various clinical features, and modes of presentation, under such synonyms as sick sinus or lazy sinus syndrome (Bouvrain et al., 1967; Ferrer, 1968; Shaw and Eraut, 1969). Furthermore, the treatment of the condition using both electrical and pharmacological methods and its mortality and morbidity have been described (Eraut and Shaw, 1971; Aroesty et al., 1974), and a complete monograph on the subject has recently been published (Ferrer, 1974).

There have been, however, very few reports of necropsy studies; indeed, a review of the published material produced only 11 cases of sinoatrial disorder of a chronic nature, in which some specialised examination of the conduction system had been undertaken at necropsy (Rossi, 1969; Patton et al., 1970; Rasmussen, 1971; Rosen et al., 1971; Rubinstein et al., 1972; Kaplan et al., 1973; Kulbertus et al., 1973; Warembourg et al., 1974; Sauerwein et al., 1976). Of these, the morphology of the sinoatrial node, atrial musculature, and the other parts of the specialised conducting system of Received for publication 14 December 1976 the heart, together with its vascular supply were adequately described in only 7 (Rosen et al., 1971; Kaplan et al., 1973; Kulbertus et al., 1973; Warembourg et al., 1974; Sauerwein et al., 1976).

The study described here was undertaken to investigate the morphological changes associated with sinoatrial disorder. Since arteriosclerosis was a common finding in the cases previously reported, a particular attempt was made to study the vascular supply to the sinoatrial node and lower part of the conducting system.

\section{Subjects and methods}

Material for the study was obtained from patients dying while in the Devon Heart Block and Bradycardia Survey (Shaw and Eraut, 1970). Patients were considered to have sinoatrial disorder if the electrocardiogram showed sinus bradycardia with one or more of the following associated arrhythmias.

(1) Periods of sinus arrest or sinoatrial block in which cessation of atrial activity persisted for 2 seconds or longer.

(2) Profound atrial slowing (below 40 per minute with or without a supervening junctional rhythm).

(3) Fast atrial arrhythmias, namely atrial fibrilla- 
tion, atrial flutter, or paroxysmal atrial tachycardia.

For the purposes of this study sinus bradycardia was defined as a chronic sinus rate below 50 per minute in the absence of myxoedema, raised intracranial tension, jaundice, or myocardial infarction, or myopericarditis within the preceding 28 days.

Hearts from 8 patients fulfilling these criteria subsequently became available at necropsy. All patients had had electrocardiographically documented bradycardia, with a heart rate below 40 beats per minute, and all patients in whom a more extensive investigation was possible had shown such features as sinus arrest or supraventricular tachycardia. Conduction disturbances had also been shown in 4 of the 8 patients; these ranged from right bundle-branch block to complete heart block. Average follow-up time for the patients was 3 years and permanent pacemakers had been used in 2 (see Tables 1 and 2 ).

Necropsies were carried out as soon as possible after death, and the heart was removed complete, care being taken to retain 2 to $3 \mathrm{~cm}$ of the proximal portion of the superior vena cava, in order to obtain the sinoatrial node intact. Furthermore, this method avoided damage to the coronary arteries so that post-mortem angiography could be undertaken. Five of the 8 cases were suitable for perfusion, and in these the coronary vasculature was injected with a radiopaque medium. Originally a barium-gelatin mixture was used; latterly, however, the coloured barium suspension, Colorpaque, was used, and this is now felt to be the method of choice (FarrerBrown, 1968), since the material consistently penetrated into vessels of a diameter of between 25 and $30 \mathrm{~m} \mu \mathrm{m}$. The vessels were perfused with the mixture at a pressure of $130 \mathrm{mmHg}$ for 10 minutes. After injection, the hearts were $x$-rayed on fine grain industrial film (Industrex-D Kodak) using an ElemaSchonander skull unit; in addition, in 2 cases use was made of the xero-radiography process, plates
Table 2 Atrial rate and rhythm and conduction disturbances recorded

\begin{tabular}{|c|c|c|c|}
\hline $\begin{array}{l}\text { Case } \\
\text { No. }\end{array}$ & Arrhythmia & $\begin{array}{l}\text { Slowest atrial } \\
\text { rate }\end{array}$ & Conduction disturbance \\
\hline 4 & $\begin{array}{l}\text { SB, SA, JEB, JR, } \\
\text { A fib, WP }\end{array}$ & 28 & None \\
\hline 5 & $\begin{array}{l}\text { SB, JEB, JR, A fl, } \\
\text { SA, A fib }\end{array}$ & 25 & 1st degree AV block \\
\hline 11 & SB & 35 & RBBB, CHB \\
\hline 17 & SB, JR & 33 & None \\
\hline 35 & SB, AT & 39 & None \\
\hline 36 & SB, AT, A fib & 24 & 1st degree AV block \\
\hline 37 & SB & 35 & None \\
\hline 39 & SB, SA & 39 & $\begin{array}{l}\text { RBBB, 1st degree AV } \\
\text { block }\end{array}$ \\
\hline
\end{tabular}

SB, sinus bradycardia; SA, sinus arrest; JEB, junctional escape beats; JR, junctional rhythm; A fib, atrial fibrillation; WP, wandering pacemaker; $A$ fl, atrial flutter; $A T$ atrial tachycardia; RBBB, right bundle-branch block; CHB, complete heart block.

being taken on a Sennengraph machine of the type used for mammography.

A block of tissue containing the sinoatrial node was then removed, and pinned out flat. This block included the whole of the superior vena caval ring, the crest of the right atrium, the sinoatrial node and its immediate approaches, and part of the roof of the right atrium. This portion was then re- $x$-rayed in order to show the vasculature in the area of the sinoatrial node. The heart was fixed for 2 to 3 weeks, and then blocks were taken for histological examination. During this process the interventricular septum was dissected free of the walls of the ventricles and re- $x$-rayed to examine the vascular supply to the atrioventricular node and bundle of His.

Some 30 to 40 blocks of tissue were taken, including representative portions of both atria, the interatrial septum, the coronary arteries, the sinoatrial-node artery, the approaches to the sinoatrial node, the atrioventricular node, the main bundle, and the bundle-branches, the right and left ven-

Table 1 Clinical details

\begin{tabular}{|c|c|c|c|c|c|}
\hline Case No. & Age (y) & Follow-up time (m) & Clinical features & Paced/non-paced & Cause of death \\
\hline 4 & 65 & 58 & $\begin{array}{l}\text { Adams-Stokes attacks; dizzy attacks; } \\
\text { dyspnoea; peripheral oedema }\end{array}$ & Paced & Pacemaker failure \\
\hline 5 & 75 & 6 & Adams-Stokes attacks; dizzy attacks & Non-paced & Cerebral thrombosis \\
\hline 11 & 93 & 3 & Dementia & Non-paced & Congestive cardiac failure \\
\hline 17 & 69 & 41 & Dyspnoea & Non-paced & Gram-negative septicaemia \\
\hline 35 & 69 & 58 & Angina; dyspnoea & Non-paced & Myocardial infarction \\
\hline 36 & 64 & 89 & $\begin{array}{l}\text { Adams-Stokes attacks; dizzy attacks; } \\
\text { palpitations, dyspnoea; angina; peripheral } \\
\text { oedema }\end{array}$ & Paced & Left ventricular failure \\
\hline $\begin{array}{l}37 \\
39\end{array}$ & $\begin{array}{l}45 \\
88\end{array}$ & $\begin{array}{l}21 \\
12\end{array}$ & $\begin{array}{l}\text { Down's syndrome; Adams-Stokes attacks } \\
\text { Dizzy attacks }\end{array}$ & $\begin{array}{l}\text { Non-paced } \\
\text { Non-paced }\end{array}$ & $\begin{array}{l}\text { Tuberculosis } \\
\text { Bronchopneumonia }\end{array}$ \\
\hline
\end{tabular}


tricles, and the interventricular septum. The method used was a modification of that described by Davies (1967).

The blocks which contained the sinoatrial node were sectioned at a thickness of $6 \mu \mathrm{m}$, every 10th section was stained for study, and every 5 th kept in reserve. A similar procedure was followed with the atrioventricular node and bundle and bundlebranches. Representative sections were taken from all of the other blocks for study.

The tissue was stained with either haemotoxylin and eosin, Verhoeff, van Gieson, or the Lendrum modification of the trichrome stain. Sections from all cases were also stained with Alcin blue (Lendrum et al., 1972) in an attempt to show any infiltration with amyloid material. The angiographic plates were compared with 50 other angiograms performed on patients without evidence of sinoatrial disorder, and histology was compared with the sections obtained from 40 patients who had normal sinoatrial function before death.

\section{Results}

\section{VASCULATURE}

In 1 of the 8 cases (case 35) the angiograms indicated a poorly preserved vasculature, with all 3 major vessels being severely narrowed, particularly those on the left side, which were almost completely blocked in several areas. These findings were confirmed on later microscopy. In 1 further case (case 11) angiography showed mild to moderate narrowing of the major vasculature, the anterior descending branch of the left coronary being most seriously affected. Histological studies confirmed the narrowing to be the result of atheromatous deposit. In the remaining 6 cases the main coronary vessels showed surprisingly little atheroma (Fig. 1). In all the cases in which angiography was possible (5 of the 8), the artery to the sinoatrial node was well seen (Fig. 2), even in the 2 cases (cases 11 and 35) where there was atheromatous narrowing of the major vasculature.

The artery to the sinoatrial node was found to be patent in all 8 cases. It originated from the right coronary artery in 6 subjects, and from the circumflex branch of the left coronary artery in the remaining 2 . On microscopy the artery was normal in 6 of the cases, and showed mild medial hypertrophy in the remaining 2 cases. The artery to the atrioventricular node and main bundle was patent in all 8 cases (Fig. 3), and in every instance the posterior descending artery which gave rise to the vessel was a branch of the right coronary. In 6 subjects the artery was normal, and in the remaining 2 showed mild medial hypertrophy.

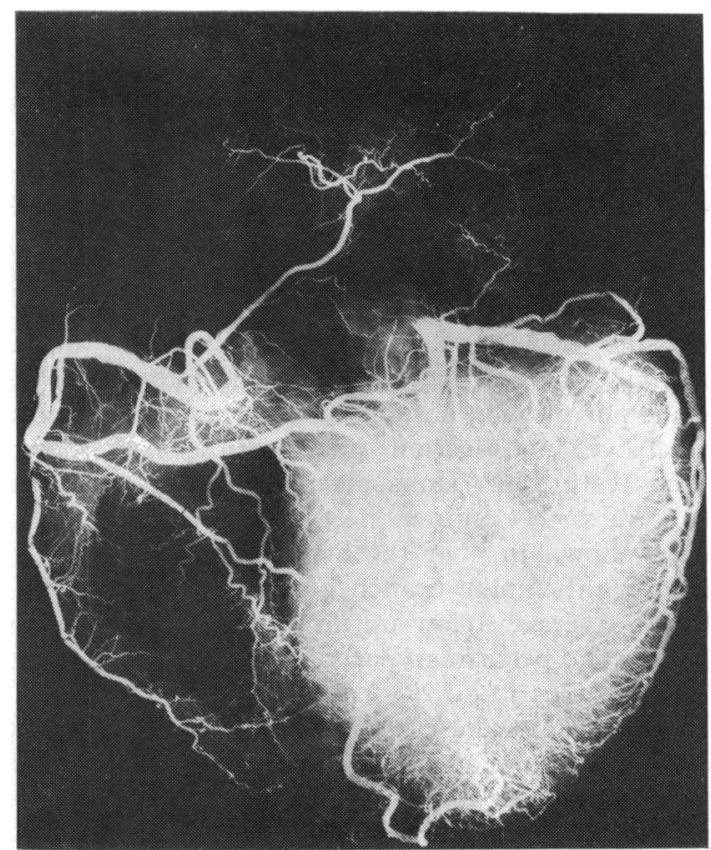

Fig. 1 Post-mortem coronary angiogram (case 36). The artery supplying blood to the atria and sinoatrial node originates from the right coronary within 2 to $3 \mathrm{~cm}$ of its origin and runs upwards towards the centre of the upper third of the frame.

\section{MORPHOLOGY OF CONDUCTING TISSUE Sinoatrial node}

The normal sinus node consists of a discrete meshwork of fibrous tissue surrounding a central artery. The specialised muscle (or pacemaker) cells are intertwined in the fibrous tissue (Fig. 4), and usually make up between 40 and 50 per cent of the nodal surface area as determined by point counting techniques (Davies and Pomerance, 1972).

In 7 of the 8 patients described in this series the sinus node was significantly abnormal. In 4 cases (cases 4, 36, 37, and 39) the nodes were very small (Fig. 5 and 6), and are described as atrophic in Table 3, which summarises the histological findings. The normal sinoatrial node, with the usual ratio of muscle to fibrous tissue shown in Fig. 4, can be directly compared with the atrophic node in Fig. 5 (case 4), which is illustrated at the same magnification $(\times 50)$. The bulk of the node can be seen to be reduced. This is even more obvious in Fig. 6 (case 36), where the magnification is twice that of the normal node as illustrated in Fig. 4, and yet nodal tissue makes up only a very small proportion of the frame. In 2 cases (cases 36 and 39) the 


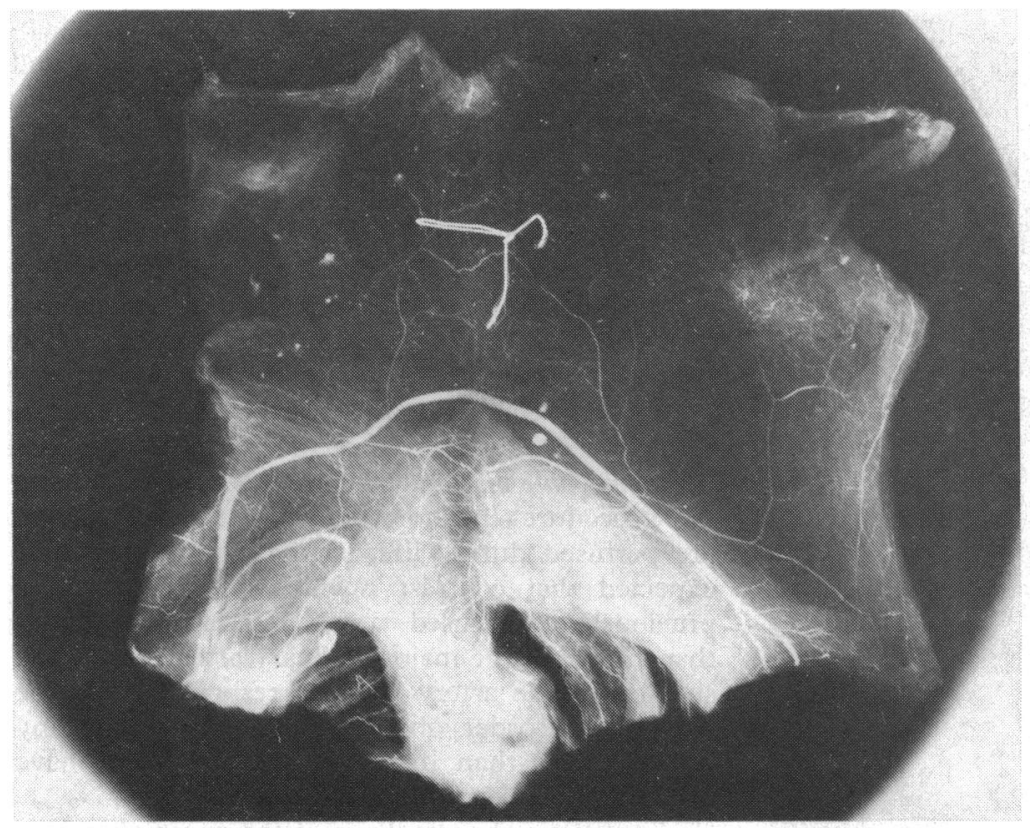

Fig. 2 Detailed view of the sinoatrial node artery seen in Fig. 1 (case 36). The upper margin of the block consists of the superior vena cava opened out and laid flat. The lower margin is made up of the wall of the right atrial appendage. The artery to the sinoatrial node can be seen curving across the block. The node would be expected to lie more or less in the centre of the frame, around the artery, below the metallic marking tie.

atrophic nodes were completely surrounded by adipose tissue which appeared to cut them off from the atrial myocardium on the sinoatrial node approaches.

Three patients (cases 11, 17, and 35) had nodes which were normal in size, but had very few specialised muscle fibres (less than $10 \%$ on point counting). A representative section from one of these nodes is shown in Fig. 7, taken at the same magnification as the normal node in Fig 4; there is little muscle tissue, which appears stained black, compared with the amount seen in the normal node (Fig. 4), but there is no reduction in the over-all size of the node, presumably because of a concomitant increase in the amount of fibrous tissue. In case 11 deposits of amyloid tissue were seen in the node, in addition to fibrous replacement of the node.

In 1 patient (case 5), the sinus node was normal in histological appearances.

\section{Atrial musculature}

The atrial musculature of the sinoatrial-node approaches, interatrial septum, and atria in general, including the areas where the so-called intra-atrial and internodal tracts would be expected to run, showed mild to moderate changes in 7 of the 8 cases. These consisted of mild fibrosis or slight fatty infiltration, and in 1 of these 7 cases there was a very slight deposition of amyloid material. In the 8th case there was heavy infiltration throughout the atrium with amyloid material, the muscle of the interatrial septum being completely replaced by this substance.

\section{Atrioventricular node and bundle}

The atrioventricular node and main bundle in 4 of the cases showed only minor changes, with some atrophy, slight fibrosis, and occasional mild fatty infiltration. In the remaining 4 cases, which were the ones who had conduction disturbances recorded in life, the changes were generally more widespread and severe. In cases 5 and 36 there was a moderate amount of fibrous replacement of the main bundle, particularly as it reached the summit of the interventricular septum before dividing into the right bundle-branch and the fascicles of the left bundle. In case 11 the changes were much more severe; there was a very atrophic atrioventricular node, with pronounced fibrosis, complete replacement of the main bundle by fibrous tissue, and occasional amyloid deposits throughout the conducting system. Sections from case 39 showed a small atrioventricular node with pronounced fibrosis. Fibrosis was also present in the main bundle, and there was complete replacement of muscle by fibrous tissue in the right bundle-branch.

\section{Discussion}

Acute disturbance of sinus node function is relatively common immediately after myocardial in- 


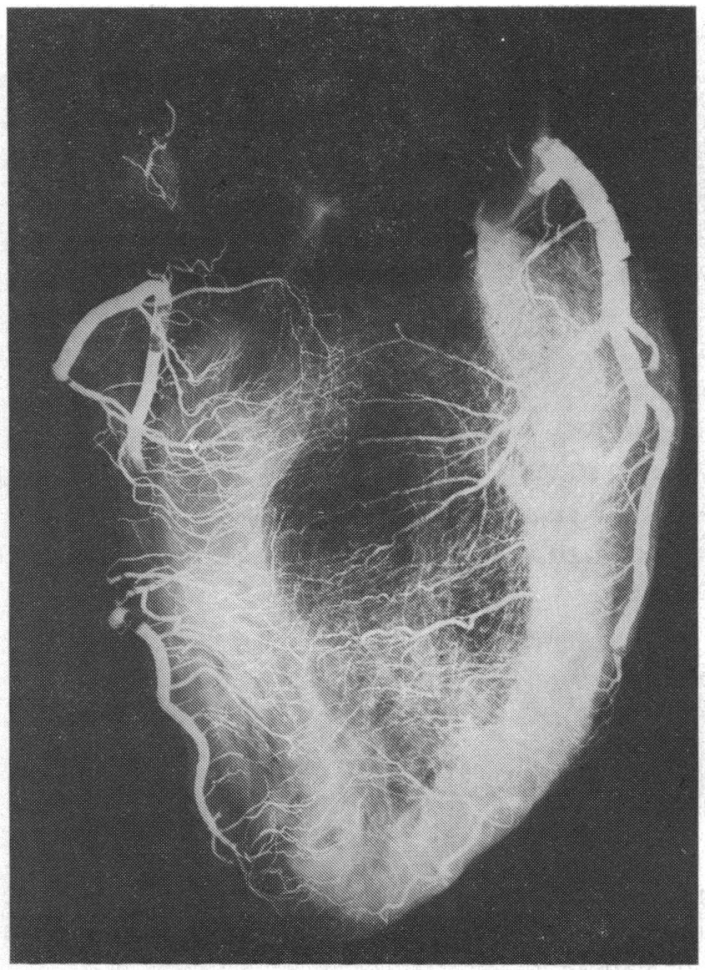

Fig. $3 \mathrm{X}$-ray film of interventricular septum of heart (case 36) showing the artery to the atrioventricular node.

On the left of the picture, the posterior descending artery runs vertically down the back of the interventricular septum, and on the right the anterior descending artery corresponds with it, running down the front of the interventricular septum.

The septum is well vascularised and the artery to the atrioventricular node can be seen originating from the posterior descending artery, just before that vessel makes an acute bend.

farction (James, 1968; Rokseth and Hatle, 1971), and sinus-node arterial thrombosis has been reported in patients dying soon after the event (James, 1961; Lippestad and Marton, 1967). Normal function usually returns within a few days (Fluck et al., 1967), though authors reporting longterm follow-up of patients after infarction draw conflicting conclusions (Hatle et al., 1976; Parameswaran et al., 1976). Similarly the incidence of a past history of a myocardial infarct differs between series of cases with chronic sinoatrial disorder (Conde $e t$ al., 1973; Härtel and Tarvensaari, 1975; Shaw, 1976). In the few previous necropsy descriptions of patients dying with chronic sinoatrial disorder, several authors found arteriosclerosis of the coronary vasculature and thereby imply that ischaemia is the cause of the disturbance of sinus node and atrial function (Rosen et al., 1971; Kaplan et al., 1973; Kulbertus et al., 1973; Aroesty et al., 1974), but detailed investigations of the nodal blood supply had not been made, nor had post-mortem coronary angiography been performed.

In the present study the major vessels were free from gross atheroma in all but one case, and in this instance (case 35 ) the sinoatrial node artery filled well with contrast media on post-mortem angiography. Of course it must be accepted that this technique cannot reproduce the precise conditions occurring ante mortem. Nevertheless, the error with this procedure tends to be a failure to fill vessels that are perfused during life, so that it would not be expected that contrast media would penetrate a previously unperfused vessel. It seems, therefore, that disease of the major coronary arteries or of the sinoatrial node artery was not responsible for the sinoatrial disorder observed in our cases. Many causes, other than disturbed blood supply, have been suggested by previous authors.

(1) Enzymatic abnormalities of the pacemaker cells such as a disturbance of cholinesterase metabolism.

(2) Infiltration of the sinoatrial node and/or its approaches, by amyloid or metastatic carcinoma.

(3) Neural factors such as abnormal vagal tone, or infiltration of the sympathetic plexus by tumour or intraneural plexus abnormalities.

(4) Idiopathic degeneration involving loss of specialised pacemaking cells in the sinus node.

(5) Fibrosis, possibly caused by past infections or an autoimmune process.

(6) Congenital abnormalities of the sinus node.

Dighton (1974) has suggested that there may be a deficiency of the enzyme cholinesterase in the autonomic nerve fibres in the sinoatrial node. Unfortunately, this hypothesis is difficult to verify with currently available techniques on material which is often 24 to 48 hours old when removed at necropsy. Such an abnormality would not be detectable on light microscopy but would be a possible explanation for the nodal dysfunction seen in the case with apparently normal sinus node structure in this series (case 5). Infiltration with amyloid may well be a cause of sinoatrial disorder in a few cases. Indeed, Kaplan et al. (1973) report a case in which amyloid tissue was found in the atrium and interatrial septum of a case with sinoatrial disorder, where amyloid itself was not found in the conducting system. In 1 case in this series (case 11) amyloid was found in the atria, the ventricles, and the conducting tissue system, and in a further case, amyloid appeared to be an incidental finding. 


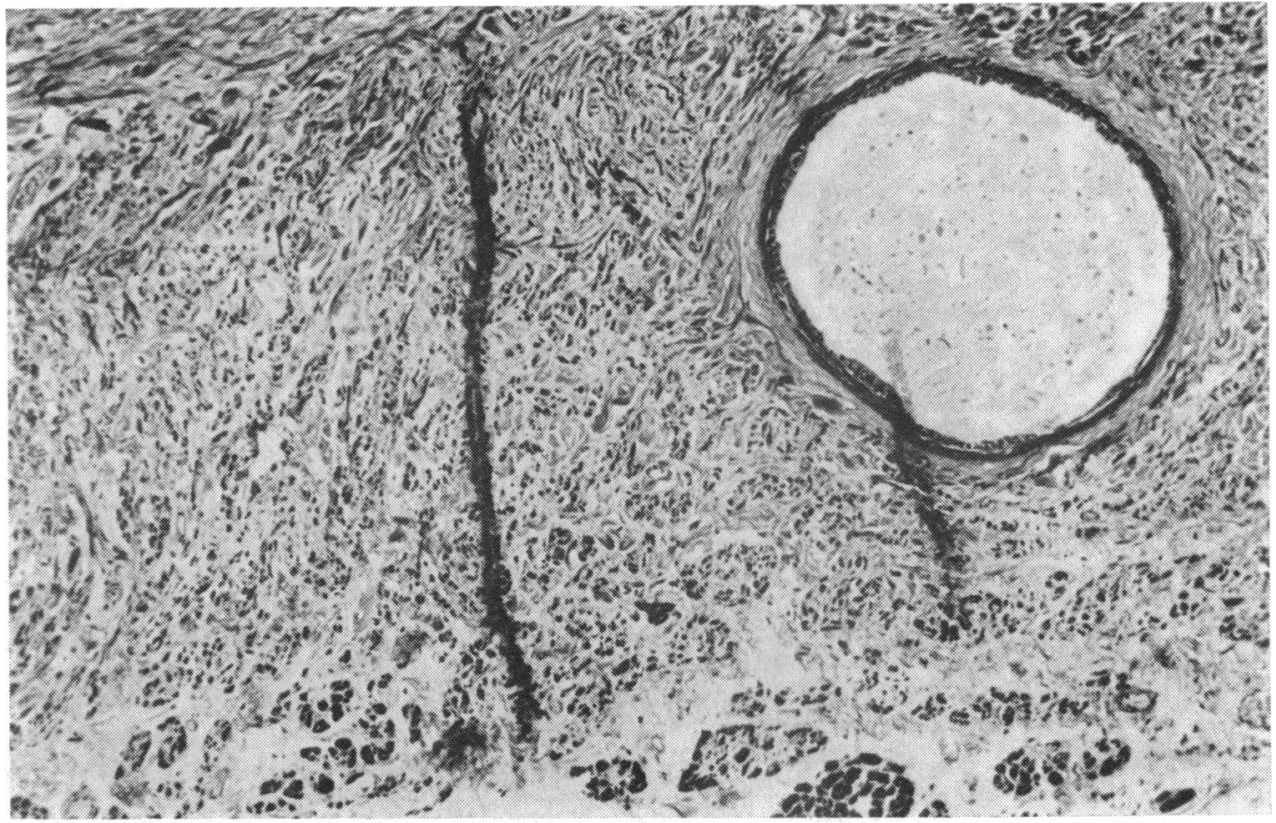

Fig. 4 Normal sinoatrial node. (Lendrum trichrome. $\times 50$.) Virtually the whole area of the figure is taken up by the sinoatrial node in which muscle tissue appears to be stained black. The sinoatrial node artery is in the right corner of the section and a fringe of atrial muscle appears along the bottom.

Pearson (1945) reported a case of sinus bradycardia with cardiac asystole, and in a later paper (1950), described the post-mortem finding of infiltration of the mediastinum by an oat-cell bronchial carcinoma involving many of the major nerve trunks. Morphological changes in the neurones around the sinoatrial node have been described in one case (Rossi, 1969), and though it is reasonable to assume that such abnormalities may affect cardiac rhythm, no evidence was available from the cases examined in this study to confirm a neural aetiology of sinoatrial disorder.

The principal findings in 7 of the 8 cases described here were of atrophy or heavy fibrosis in the sinoatrial node. It was suggested by Fowler et al. (1969) that the pathology of sinoatrial node disorder might be comparable with that found in idiopathic heart block and indeed atrophy and fibrosis do occur in the latter condition. Furthermore, the changes detected in this series were not limited to

Table 3 Summary of pathological findings of 8 cases studied

\begin{tabular}{|c|c|c|c|c|c|}
\hline Case No. & Sinoatrial node & Atrial musculature & Atrioventricular node & Main bundle & Bundle-branches \\
\hline 4 & Atrophic & $\begin{array}{l}\text { Mild fibrosis, } \\
\text { slight amyloidosis }\end{array}$ & Mild fibrosis & Normal & $\begin{array}{l}\text { Mild fibrosis } \\
\text { peripherally }\end{array}$ \\
\hline 5 & Normal & Mild fibrosis & Normal & Mild fibrosis & $\begin{array}{l}\text { Heavy fibrosis in bundle- } \\
\text { branches peripherally }\end{array}$ \\
\hline 11 & $\begin{array}{l}\text { Moderate fibrosis, } \\
\text { amyloid deposits }\end{array}$ & $\begin{array}{l}\text { Almost total replacement } \\
\text { with amyloid }\end{array}$ & $\begin{array}{l}\text { Atrophy, heavy fibrosis, } \\
\text { fatty infiltration }\end{array}$ & $\begin{array}{l}\text { Practically total fibrosis, } \\
\text { some amyloid deposits }\end{array}$ & Heavy fibrosis \\
\hline 17 & Heavy fibrosis & Mild fibrosis & Normal & Normal & Normal \\
\hline 35 & Heavy fibrosis & Mild fatty infiltration & $\begin{array}{l}\text { Mild fibrosis, slight fatty } \\
\text { infiltration }\end{array}$ & Normal & $\begin{array}{l}\text { Mild fibrosis in bundle- } \\
\text { branches }\end{array}$ \\
\hline 36 & $\begin{array}{l}\text { Atrophic and surrounded } \\
\text { by adipose tissue }\end{array}$ & Mild fibrosis & $\begin{array}{l}\text { Some atrophy, slight } \\
\text { fatty infiltration, } \\
\text { mild fibrosis }\end{array}$ & $\begin{array}{l}\text { Moderate fibrosis, mild } \\
\text { fatty infiltration }\end{array}$ & Some atrophy \\
\hline 37 & Atrophic, mild fibrosis & Fatty infiltration & $\begin{array}{l}\text { Somewhat atrophic- } \\
\text { some fatty infiltration }\end{array}$ & Mild fatty infiltration & Normal \\
\hline 39 & $\begin{array}{l}\text { Atrophic and surrounded } \\
\text { by adipose tissue }\end{array}$ & $\begin{array}{l}\text { Fatty infiltration, mild } \\
\text { fibrosis }\end{array}$ & $\begin{array}{l}\text { Heavy fibrosis, fatty } \\
\text { infiltration }\end{array}$ & Heavy fibrosis & $\begin{array}{l}\text { RBB completely fibrosed, } \\
\text { LBB moderate fibrosis }\end{array}$ \\
\hline
\end{tabular}




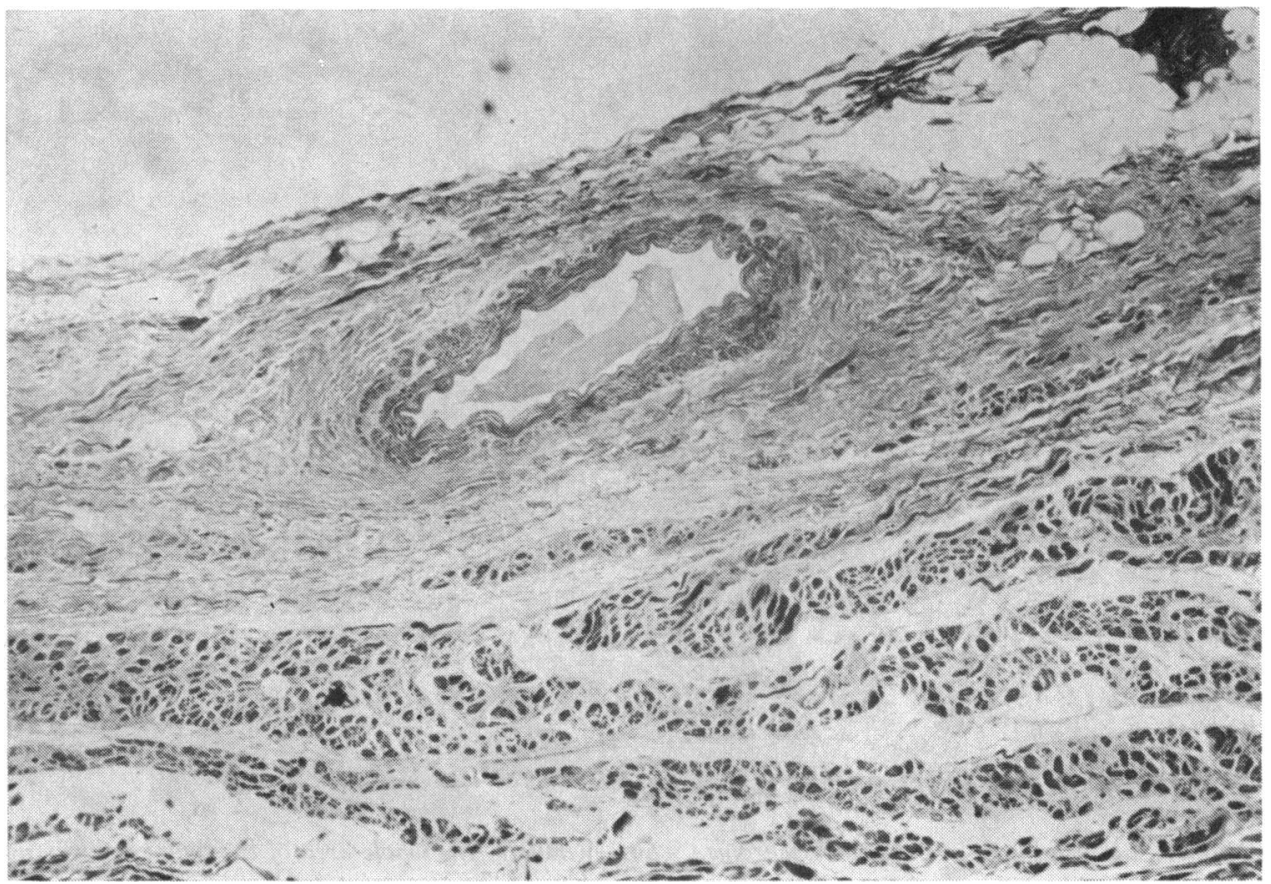

Fig. 5 Sinoatrial node (case 4). (Lendrum trichrome. $\times 42$.$) An atrophic and fibrosed node distributed around a$ central artery.

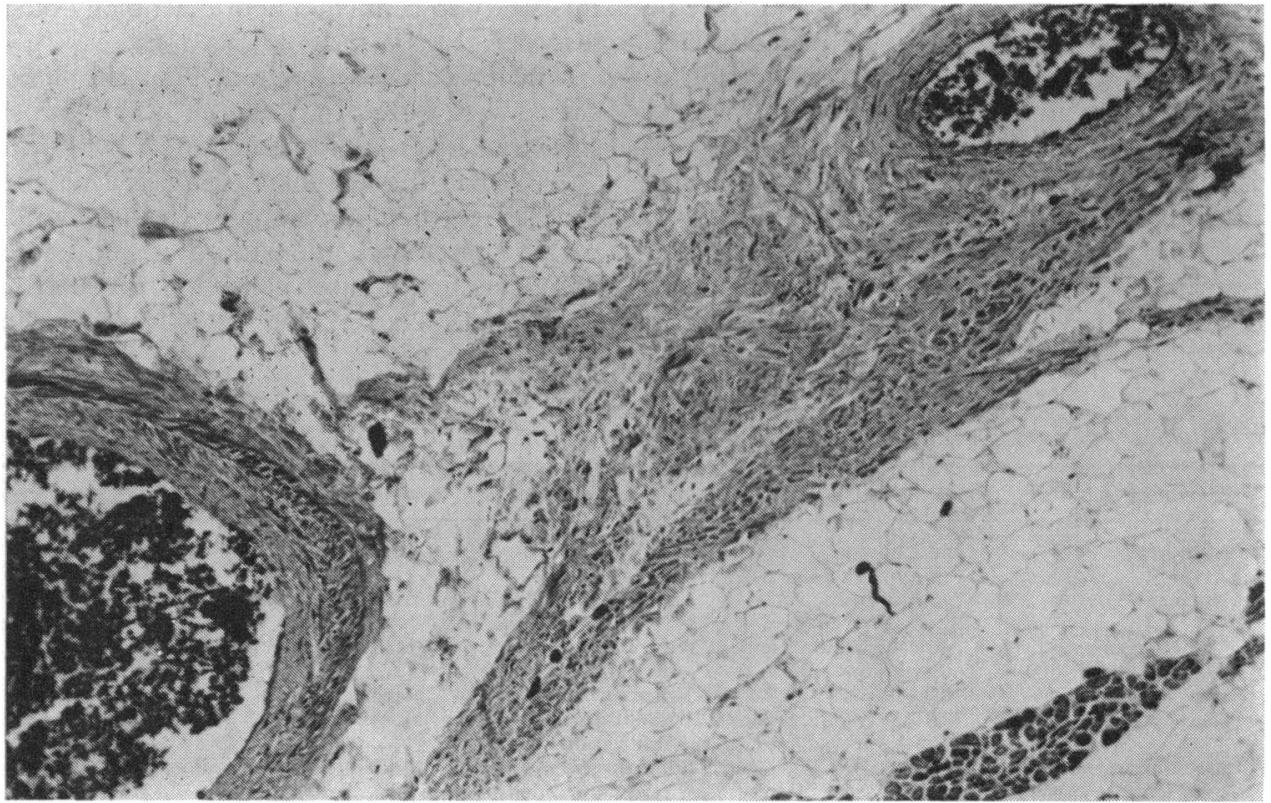

Fig. 6 Sinoatrial node (case 36). (Lendrum trichrome. $\times 84$.) Grossly atrophic node. The sinoatrial-node artery, which contains injectate, has split into 2 branches. What nodal tissue is present lies between the arteries completely surrounded by fat. This is the best preserved portion of a node which was much reduced in size, and also contains very little muscle tissue. 


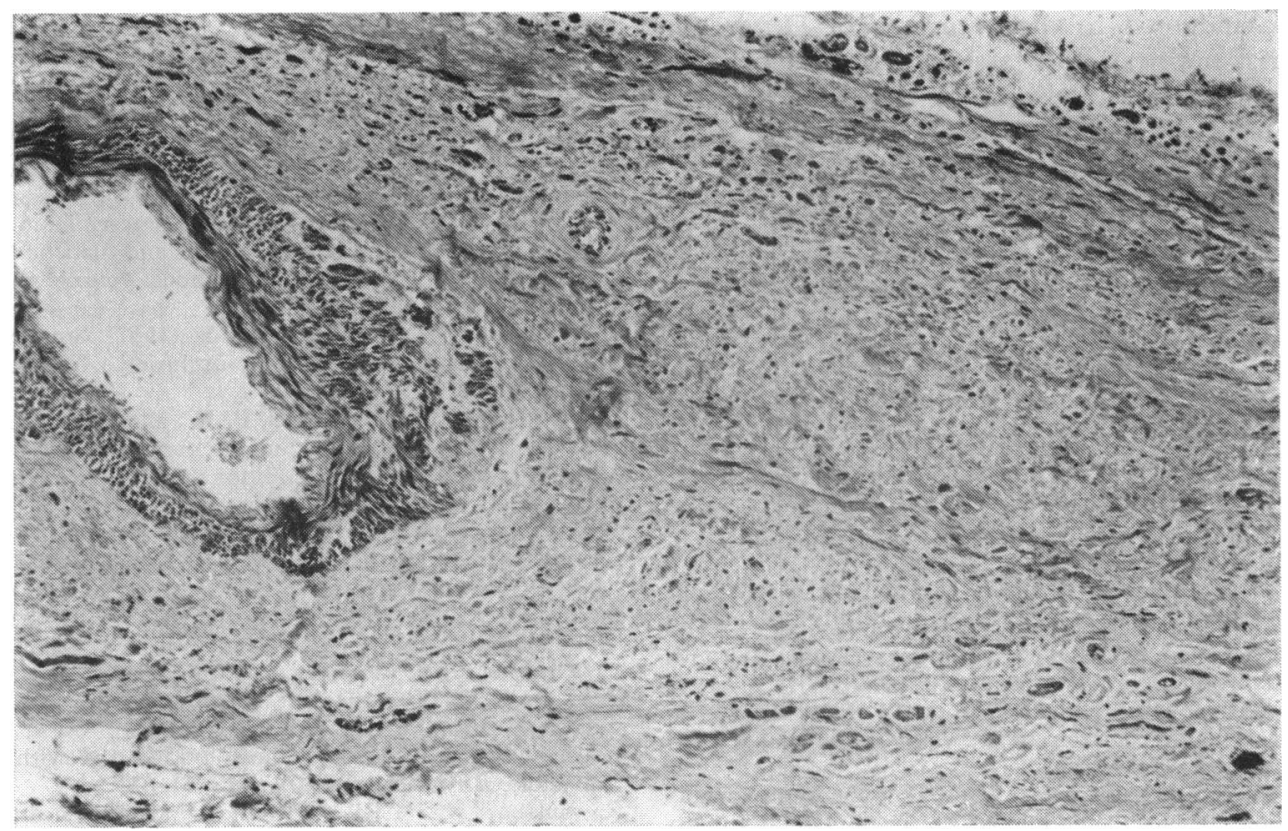

Fig. 7 Sinoatrial node (case 35). (Lendrum trichrome. $\times 42$.$) The artery is to the left of the illustration. There is$ heavy replacement fibrosis of the node as shown by the paucity of muscle tissue, which appears to be stained black, compared with the normal node (Fig. 4). No reduction in the overall bulk of the node.

the sinoatrial node, but also involved the atrial musculature, the sinoatrial node approaches, the interatrial septum, where the so-called internodal tracts would be expected to run, and the distal portion of the conducting system. The fibrosis seen in the sinoatrial node and sinoatrial node approaches could be the end result of one of a number of previous pathological conditions. Infective and inflammatory diseases, such as diphtheria, rheumatic fever, or viral pericarditis, might be followed by damage and replacement fibrosis, and have been blamed by some authors for causing sinoatrial disorder (Rasmussen, 1971; Rokseth and Hatle, 1971; Ferrer, 1973). Autoimmunological mechanisms have been suggested for the fibrosis and degeneration seen in heart block (Fairfax and Leatham, 1975), and similar mechanisms might apply in sinoatrial disorder. Certainly the results presented here should not be interpreted in such a way as to rule out the possibility of small blood vessel disease since the methods used were not capable of allowing accurate assessment of vessels smaller than $30 \mu \mathrm{m}$.

The hypothesis that sinoatrial disorder may have a congenital or familial basis is supported by papers by Williams et al. (1972) and Caralis and Varghese (1976). The former authors described 3 of 5 children in a family who had episodes of persistent atrial standstill, but histological studies are not available.

It appears that sinoatrial disorder may be produced by a variety of conditions and could, therefore, be considered comparable to chronic atrioventricular block. In case 5, where the sinoatrial node was normal to light microscopy, an ultrastructural or cholinesterase production defect could not be ruled out. Loss or replacement of pacemaker tissue was, however, the usual finding, without significant coronary artery disease. Where the outline of the sinus node appears very reduced in size (atrophy) a congenital aplasia or hypoplasia could be postulated. In contrast, when nodal size is normal but specialised muscle tissue is replaced by fibrous tissue (fibrosis), an acquired disease, perhaps myocarditic or autoimmune, can be postulated, while further information is required concerning the smaller blood vessels. Age-related loss of specialised nodal fibres, which is almost universal, would potentiate either nodal hypoplasia or fibrosis.

We thank Dr. Michael Davies of St. George's Hospital for his help and encouragement throughout this study, and for reading the manuscript. We are grateful to Dr. Alan Caldwell and Dr. Sylvia Davis for their co-operation throughout this study. We 
are also indebted to the clinicians of Devon for their brisk notification of fatal cases upon which this study relied. Part of this work was financed by a Grant from the Department of Health and Social Security.

\section{References}

Aroesty, J. M., Cohen, S. I., and Morkin, E. (1974). Bradycardia-tachycardia syndrome: results in twenty-eight patients treated by combined pharmacologic therapy and pacemaker implantation. Chest, 66, 257-263.

Bouvrain, Y., Slama, R., and Temkine, J. (1967). Le bloc sino-auriculaire et 'les maladies du sinus'. Réflexions à propos de 63 observations. Archives des Maladies du Coeur et des Vaisseaux, 60, 753-773.

Caralis, D. G., and Varghese, P. J. (1976). Familial sinoatrial node dysfunction. Increased vagal tone a possible aetiology. British Heart fournal, 38, 951-956.

Conde, C. A., Leppo, J., Lipski, J., Stimmel, B., Litwak, R., Donoso, E., and Dack, S. (1973). Effectiveness of pacemaker treatment in the bradycardia-tachycardia syndrome. American fournal of Cardiology, 32, 209-213.

Davies, M. J. (1967). A histological study of the conduction system in complete heart block. Fournal of Pathology and Bacteriology, 94, 351-358.

Davies, M. J., and Pomerance, A. (1972). Quantitative study of ageing changes in the human sinoatrial node and internodal tracts. British Heart fournal, 34, 150-152.

Dighton, D. H. (1974). Sinus bradycardia: autonomic influences and clinical assessment. British Heart fournal, 36, 791-797.

Eraut, D., and Shaw, D. B. (1971). Sinus bradycardia. British Heart fournal, 33, 742-749.

Fairfax, A. J., and Leatham, A. (1975). Idiopathic heart block: associated with vitiligo, thyroid disease, pernicious anaemia and diabetes mellitus. British Medical fournal, 4, 322-324.

Farrer-Brown, G. (1968). The injection of capillaries, arterioles, and arteries in the ventricles of the human heart by a radio-opaque medium. Cardiovascular Research, 2, 179-186.

Ferrer, M. I. (1968). The sick sinus syndrome in atrial disease. fournal of the American Medical Association, 206, 645-646.

Ferrer, M. I. (1973). The sick sinus syndrome. Circulation, 47, 635-641.

Ferrer, M. I. (1974). The Sick Sinus Syndrome. Futura, Mount Kisco, New York.

Fluck, D. C., Olsen, E., Pentecost, B. L., Thomas, M., Fillmore, S. J., Shillingford, J. P., and Mounsey, J. P. D. (1967). Natural history and clinical significance of arrhythmias after acute cardiac infarction. British Heart fournal, 29, 170-189.

Fowler, P. B. S., Ikram, H., Maini, R. N., Makey, A. R., and Kirkham, J. S. (1969). Bradycardic angina: haemodynamic aspects and treatment. British Medical fournal, 1, 92-94.

Härtel, G., and Tarvensaari, T. (1975). Treatment of sinoatrial syndrome with permanent cardiac pacing in 90 patients. Acta Medica Scandinavica, 198, 341-347.

Hatle, L., Bathen, J., and Rokseth, R. (1976). Sino-atrial disease in acute myocardial infarction long-term prognosis. British Heart fournal, 38, 410-414.

James, T. N. (1961). Myocardial infarction and atrial arrhythmias. Circulation, 24, 761-776.

James, T. N. (1968). The coronary circulation and conduction system in acute myocardial infarction. Progress in Cardiovascular Diseases, 10, 410-449.
Kaplan, B. M., Langendorf, R., Lev, M., and Pick, A. (1973). Tachycardia-bradycardia syndrome (so-called (sick sinus syndrome'). American fournal of Cardiology, 31, 497-508.

Kulbertus, H. E., De Leval-Rutten, F., and Demoulin, J. C. (1973). Sino-atrial disease: a report on 13 cases. Fournal of Electrocardiology, 6, 303-312.

Lendrum, A. C., Slidders, W., and Fraser, D. S. (1972). Renal hyalin: a study of amyloidosis and diabetic fibrinous vasculosis with new staining methods. Fournal of Clinical Pathology, 25, 373-396.

Lippestad, C. T., and Marton, P. F. (1967). Sinus arrest in proximal right coronary artery occlusion. American Heart Fournal, 74, 551-556.

Lloyd-Mostyn, R. H., Kidner, P. H., and Oram, S. (1973). Sinuatrial disorder including the brady-tachycardia syndrome: a review with addition of 11 cases. Quarterly Fournal of Medicine, New Series, 42, 41-57.

Parameswaran, R., Ohe, T., and Goldberg, H. (1976). Sinus node dysfunction in acute myocardial infarction. British Heart fournal, 38, 93-96.

Patton, R. D., Damato, A. N., Berkowitz, W. D., Lau, S. H., and Stein, E. (1970). The electrically silent right atrium. Fournal of Electrocardiology, 3, 239-243.

Pearson, R. S. B. (1945). Sinus bradycardia with cardíac asystole. British Heart fournal, 7, 85-90.

Pearson, R. S. B. (1950). Sinus bradycardia with cardiac asystole. British Heart fournal, 12, 61-64.

Rasmussen, K. (1971). Chronic sinoatrial heart block. American Heart fournal, 81, 38-47.

Rokseth, R., and Hatle, L. (1971). Sinus arrest in acute myocardial infarction. British Heart fournal, 33, 639-642.

Rosen, K. M., Rahimtoola, S. H., Gunnar, R. M., and Lev, M. (1971). Transient and persistent atrial standstill with $\mathrm{His}$ bundle lesions: electrophysiologic and pathologic correlations. Circulation, 44, 220-236.

Rossi, L. (1969). Histopathologic Features of Cardiac Arrhythmias. Casa Editrice Ambrosiana, Milano.

Rubenstein, J. L., Schulman, C. L., Yurchak, P. M., and Desanctis, R. W. (1972). Clinical spectrum of the sick sinus syndrome. Circulation, 46, 5-13.

Sauerwein, H. P., Roos, J. C., Becker, A. E., and Dunning, A. J. (1976). The sick sinus syndrome. Acta Medica Scandinavica, 199, 467-473.

Shaw, D. B. (1976). The etiology of sino-atrial disorder (sick sinus syndrome). American Heart fournal, 92, 539-540.

Shaw, D. B., and Eraut, D. (1969). Atrial bradycardia or the lazy sinus syndrome. Bristol Medico-Chirurgical fournal, 84, 213-215.

Shaw, D. B., and Eraut, D. (1970). Prevalence and morbidity of heart block in Devon. British Medical fournal, 1, 144-147.

Short, D. S. (1954). The syndrome of alternating bradycardia and tachycardia. British Heart fournal, 16, 208-214.

Warembourg, H., Théry, C., Lekieffre, J., Delbecque, H., and Gosselin, B. (1974). Blocs sino-auriculaires et blocs auriculo-ventriculaires associés. Archives des Maladies $d u$ Coeur et des Vaisseaux, 67, 787-795.

Williams, D. O., Jones, E. L., Nagle, R. E., and Smith, B. S. (1972). Familial atrial cardiomyopathy with heart block. Quarterly fournal of Medicine, 41, 491-508.

Requests for reprints to Dr. David B. Shaw, Cardiac Department, Royal Devon and Exeter Hospital (Wonford), Barrack Road, Exeter EX2 5DW. 